\title{
Genetic and genomic analysis of hyperthelia in Brown Swiss cattle
}

\author{
Adrien M. Butty, ${ }^{*} \dagger$ Mirjam Frischknecht, ${ }^{*} \ddagger$ Birgit Gredler, ${ }^{*}$ Stefan Neuenschwander,§ Jürg Moll, ${ }^{*}$ \\ Anna Bieber,\# Christine F. Baes, $\dagger^{1}$ and Franz R. Seefried* \\ ${ }^{*}$ Qualitas AG, Zug 6300, Switzerland \\ †Centre for Genetic Improvement of Livestock, Department of Animal Biosciences, University of Guelph, Guelph N1G 2W1, Ontario, Canada \\ ¥School of Agricultural, Forest and Food Sciences, Bern University of Applied Sciences, Zollikofen 3052, Switzerland \\ §Unit of Animal Genetics, Institute of Agricultural Sciences, Swiss Federal Institute of Technology, Zurich 8092, Switzerland \\ \#Department of Animal Sciences, Research Institute of Organic Agriculture (FiBL), Frick 5070, Switzerland
}

\begin{abstract}
Supernumerary teats (SNT) are any abnormal teats found on a calf in addition to the usual and functional 4 teats. The presence of SNT has also been termed "hyperthelia" since the end of the 19th century. Supernumerary teats can act as an incubator for bacteria, infecting the whole udder, and can interfere with the positioning of the milking machine, and consequently, have economic relevance. Different types of SNT are observed at different positions on the udder. Caudal teats are in the rear, ramal teats are attached to another teat, and intercalary teats are found between 2 regular teats. Not all teats are equally developed; some are completely functional but most are rudimentary and not attached to any mammary gland tissue. Recently, different studies showed the poly/oligogenic character of these malformations in cattle as well as in other mammalian species. The objective of this study was to analyze the genetic architecture and incidence of hyperthelia in Swiss Brown Swiss cattle using both traditional genetic evaluation as well as imputed whole genome sequence variant information. First, phenotypes collected over the last $20 \mathrm{yr}$ were used together with pedigree information for estimation of genetic variance. Second, breeding values of Brown Swiss bulls were estimated applying the BLUP algorithm. The BLUP-EBV were deregressed and used as phenotypes in genomewide association studies. The gene LGR5 on chromosome 5 was identified as a candidate for the presence of SNT. Using alternative trait coding, genomic regions on chromosome 17 and 20 were also identified as being involved in the development of SNT with their own supernumerary mammary gland tissue. Implementing knowledge gained in this study as a routine application allows a more accurate evaluation of the trait and
\end{abstract}

Received May 8, 2016.

Accepted September 30, 2016.

${ }^{1}$ Corresponding author: cbaes@uoguelph.ca reduction of SNT prevalence in the Swiss Brown Swiss cattle population.

Key words: dairy cattle, hyperthelia, supernumerary teats, genome-wide association

\section{INTRODUCTION}

Supernumerary teats (SNT) are any abnormal teats found on a calf in addition to the usual and functional 4 teats. The presence of SNT has also been termed "hyperthelia" since the end of the 19th century (Schmidt, 1896). Studies on different populations report a prevalence of SNT of 40 to $44 \%$ in German Fleckvieh, 15\% in Swiss Holstein, and 31\% in German Brown Swiss (BS; Brka et al., 2002; Pausch et al., 2012; Joerg et al., 2014). Only $20 \%$ of the Swiss BS population is affected by SNT, the result of drastic selection for clear udders in the years before recording this trait (Lucas Casanova, Braunvieh Schweiz, Zug, Switzerland; personal communication). Prevalence differences between breeds for SNT indicate genetic variation within this trait and must be analyzed for each population individually. Supernumerary teats have been described at different locations: on the rear of the udder (caudal), between the front and rear teats (intercalary), or appended to a regular teat (ramal; Skjervold, 2010). The developmental stage of the SNT can also vary. In some cases SNT had their own supernumerary mammary gland tissue (live SNT), but in most cases no separate mammary gland tissue exists for the SNT (blind SNT; Pausch et al., 2012; Joerg et al., 2014). Brka et al. (2002) showed that cows whose mother was lactating during their embryonic development had SNT prevalence 5\% higher than animals whose mother was a heifer during pregnancy. Development of mammary gland tissue has predominantly been studied in mice. Results of such studies indicate a 2-step development process. In a first phase, epithelial cells superimpose and placodes appear along the milk lines and develop into mammary buds. Later in pregnancy, the buds branch to form a rudimentary ductal tree, which grows further at puberty (Hens 
and Wysolmerski, 2005). Different signaling pathways may influence both phases; therefore, multiple genomic regions could be involved in the presence of SNT.

In the dairy industry, SNT are considered problematic for various reasons. First, they present a risk factor for mastitis. Bacteria present in the unused teat $(\mathrm{s})$ can migrate to an active teat and induce an infection (Steiger and Grünenfelder, 1988). Second, SNT lower milking ability. This is not only true for the ramal SNT, which interfere with the correct placement of the conventional milking machine (Wiener, 1962), but for all types of SNT that may not be recognized as such by automatic milking systems (AMS). Swiss AI centers reacted to the second problem by creating a label for bulls whose daughters are well adapted to AMS (Bigler, 2015). In this context, better understanding of the genetic background of SNT becomes particularly relevant. Third, animals affected by SNT have fewer chances to perform well at exhibitions and have a lower price on the market (Pausch et al., 2012; Joerg et al., 2014). Finally, consumers have identified surgical elimination of SNT as a major risk for poor calf welfare (Vasseur et al., 2010). As consciousness for animal welfare rises, the surgical removal of SNT may be banned. Therefore, dairy cattle breeders should aim to quickly decrease the SNT prevalence in their population using highly accurate breeding values.

In this study, we performed a traditional genetic evaluation of SNT applying BLUP. Sire genotypes and deregressed EBV were used to discover QTL affecting the presence of blind or live SNT. Use of this information in routine genomic prediction will improve the accuracy of selection against SNT, help to decline their prevalence, and thus provide an alternative to surgical removal.

\section{MATERIALS AND METHODS}

\section{Animals and Phenotypes}

During linear scoring of BS cattle, SNT have been routinely recorded together with conformation traits for more than 20 yr in Switzerland. A genetic analysis has not been performed on these records before. The SNT are evaluated on a numerical scale from 1 to 9 , where 9 indicates animals without SNT. Codes from 1 to 8 are applied depending on the form and severity of the SNT. However, the scale is not linearly proportional. The SNT with supernumerary mammary gland tissue have code 3 . The SNT without supernumerary mammary gland tissue have code 4 . Removed SNT (scars) have code 5 or 6 whether the presence of a supernumerary gland is detected or not. Differences in code for present or removed SNT were not taken into account as codes 3 and 5 but also 4 and 6 were always considered similarly. Code 7 describes a rudimentary SNT without supernumerary mammary gland tissue. Codes 4 and 7 are only differentiated by their length, as SNT shorter than $0.5 \mathrm{~cm}$ are considered rudimentary. Codes 1,2 , and 8 are given for ramal SNT, a second orifice on a main teat, or a hairless spot on the udder, respectively. These codes do not represent an independent SNT and therefore were not considered for this analysis.

Udder clearance (UCT) compared clear animals (code 9) to affected animals (codes 3 to 7 ). A second trait, the presence of supernumerary mammary gland tissue with an SNT (PMG) emphasized the live SNT by contrasting animals with a clear udder and animals with blind SNT (codes 4, 6, 7, and 9) to animals with live SNT (codes 3 and 5). Figure 1 shows the code repartition of both binary traits. Since the beginning of linear description in Switzerland, 863,997 records have been routinely registered. Only records of first lactating cows were kept. A year was defined from August to July to adhere to the seasonal recording rhythm. Groups were created for expert-by-year and farm-by-year. To ensure balanced groups, years with less than 30,000 records, expert groups with less than 200 entries, and farm groups with less than 6 animals were excluded. These cut-offs were empirically chosen on the basis of graphical observation. After editing, phenotypic data contained 383,873 SNT scores. Table 1 presents the proportions of raw SNT scores before and after filtering.

\section{Genetic Parameter and Breeding Value Estimation}

Genetic parameters were estimated with VCE version 6 (Neumaier and Groeneveld, 1998; Groeneveld et al., 2010). Reducing the number of farm-by-year classes, we created 4 random samples of approximately 150,000 records. We fitted the model $\mathbf{y}=\mathbf{X} \boldsymbol{\beta}+\mathbf{Z}_{\mathrm{a}} \mathbf{a}$ $+\mathbf{Z}_{\mathbf{p}} \mathbf{p}+\mathbf{e}$, where $\mathbf{y}$ is a vector of binary phenotypes of UCT or PMG, $\boldsymbol{\beta}$ is the vector of the fixed effect of the animal dam's life stage - heifer or cow, $\mathbf{X}$ is a design matrix that associates $\boldsymbol{\beta}$ with $\mathbf{y}$, $\mathbf{a}$ is the vector of direct genetic effects, $\mathbf{Z}_{\mathbf{a}}$ is the design matrix that attributes $\mathbf{a}$ with $\mathbf{y}, \mathbf{p}$ is the vector of the random effects expert-by-year and farm-by-year, $\mathbf{Z}_{\mathbf{p}}$ is the matrix that associates $\mathbf{p}$ with $\mathbf{y}$, and $\mathbf{e}$ represents the residuals effects not explained by the model. The fixed effect of the animal's dam's life stage had 2 classes. Records of animals whose dam was a heifer during pregnancy were divergent to records of animals whose dam was lactating during their embryological development. Variance component estimates presented are averages of the results of 4 runs per trait definition. 


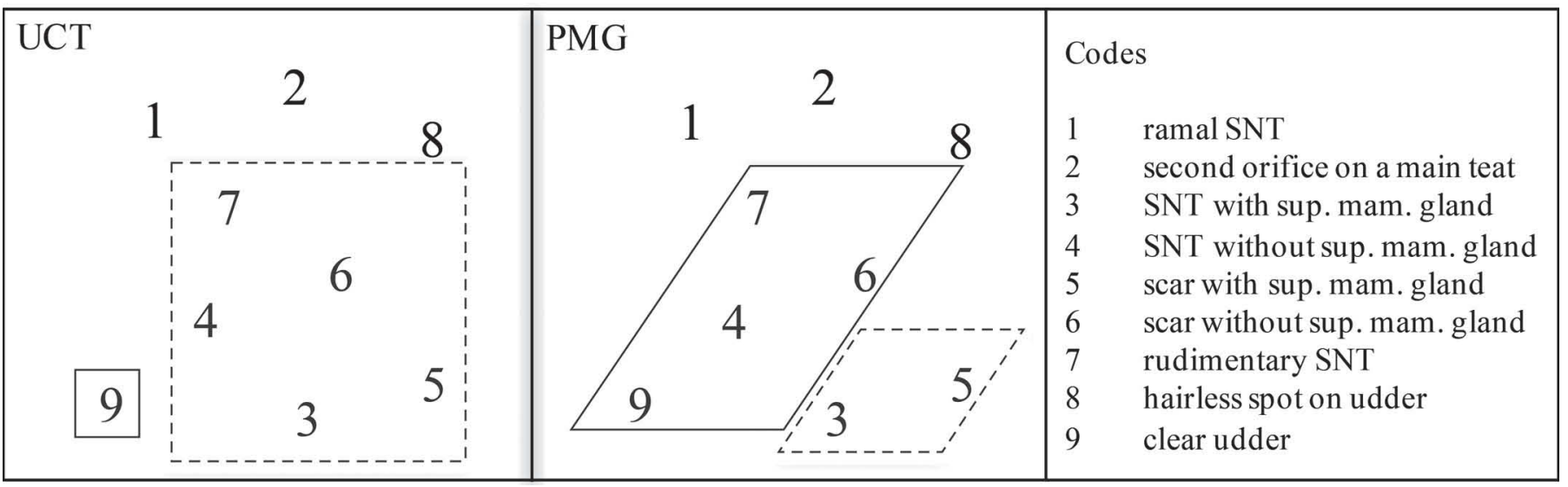

Figure 1. Distribution of the supernumerary teat (SNT) codes for both trait definitions: udder clearance (UCT) and presence of supernumerary mammary (sup. mam.) gland tissue (PMG).

Bulls were selected from the Swiss BS database. Sires EBV were computed using the same phenotypes and fitting the same model as for variance component estimation. Estimation of breeding values was run with BLUP90IOD (Tsuruta et al., 2001), and accuracies were computed using ACCF90 version 1.07 (Misztal et al., 2002). The edited phenotypic set (383,873 records) and complete pedigree data $(4,281,980$ animals traced back to year 1923) entered this estimation. Only sires of 20 or more phenotyped cows were used for genomewide association studies (GWAS). The EBV of these remaining 1519 BS sires were deregressed as proposed by Garrick et al. (2009) and used as phenotypes in the GWAS.

\section{Genotypes}

Medium-density chips (Illumina BovineSNP50, 50K, versions 1 and 2) were used to genotype 355 animals, and 1,164 animals were genotyped using high-density SNP chips (Illumina BovineHD, 777K). Combining family and population imputation, medium-density genotypes were imputed to high density in a 2-step approach with
FImpute (Sargolzaei et al., 2014). The high-density genotypes were imputed to whole genome sequences using 123 sequenced BS animals of Run5 of the 1000 Bulls Genome Project as a reference panel (Daetwyler et al., 2014). Following the conclusions of Pausch et al. (2013), we used Beagle 4 (Browning and Browning, 2009) for phasing and Minimac 3 (Howie et al., 2012) for imputation. The SNP with a minor allele frequency lower than 0.05 were removed for the association studies. In fact, dosage information of 9,840,390 autosomal SNP was used for analysis. Dosages were computed by Minimac during imputation and took continuous values from 0 to 2 , resulting from the multiplication of the genotypes and their probabilities (Weigel et al., 2010).

\section{Genome-Wide Association Studies}

The model $\mathbf{y}=\mu+\mathbf{X b}+\mathbf{Z u}+\mathbf{e}$, where $\mathbf{y}$ is a vector of deregressed EBV, $\mu$ is the overall mean, $\mathbf{b}$ is the SNP effect, $\mathbf{X}$ is a design matrix of SNP genotypes, $\mathbf{u}$ is a vector of additive polygenic effects, $\mathbf{Z}$ is an incidence matrix relating the polygenic effects to individuals, and $\mathbf{e}$ is a vector of residuals, was fitted to discover

Table 1. Prevalence (\%) of the supernumerary teat (SNT) scores in the raw data and after data filtering

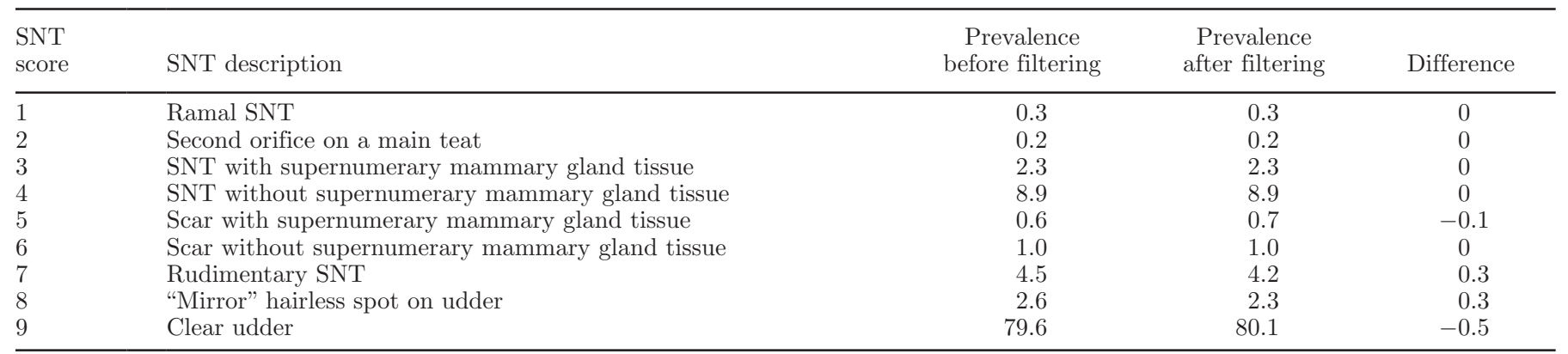


Table 2. Overview of the reliabilities of the EBV and the deregressed EBV of the bulls selected for genomewide association studies for udder clearance (UCT) and supernumerary mammary gland tissue (PMG)

\begin{tabular}{lcccccccc}
\hline & \multicolumn{3}{c}{ UCT } & & \multicolumn{3}{c}{ PMG } \\
\cline { 2 - 3 } \cline { 7 - 8 } Reliability & Minimum & Mean & Maximum & & Minimum & Mean & Maximum \\
\hline EBV & 0.73 & 0.89 & 0.99 & & 0.58 & 0.83 & 0.99 \\
Deregressed EBV & 0.68 & 0.89 & 0.99 & & 0.52 & 0.80 & 0.99 \\
\hline
\end{tabular}

sequence variants associated with our traits. Population stratification was corrected using the mixed modelbased approach implemented in EMMAX (Kang et al., 2010). Polygenic effects were assumed normally distributed: $N\left(0, \mathbf{G} \sigma_{a}^{2}\right)$ with $\sigma_{a}^{2}$ being the additive genetic variance and $\mathbf{G}$ being the bull genomic relationship matrix. $\mathbf{G}$ was computed using the SNP panel of the Illumina BovineHD chip and genome-wide complex trait analysis (Yang et al., 2011a).

The method of Devlin and Roeder (1999) was used to calculate the genomic inflation factor, and SNP with $P<5.0811 \times 10^{-9}$ (Bonferroni correction for multiple testing) were considered significantly associated. Gene content analysis was based on the reference sequence of the University of Maryland: UMD3.1 (Zimin et al., 2009) and variant annotation based on the results of the Variant Effect Predictor (McLaren et al., 2010) used with the Ensembl annotation database (Cunningham et al., 2015).

\section{Genetic Variance Explained Per Chromosome}

The amount of genetic variance explained per chromosome was estimated using algorithms as implemented in GCTA (Yang et al., 2011a). First, the genomic relationship matrices (GRM) were built as presented in Yang et al. (2010) for each chromosome separately. We then fitted the model $\mathbf{y}=\sum_{i=1}^{29} \mathbf{g}_{i}+\mathbf{e}$, where $\mathbf{y}$ represents a vector of deregressed proofs for 1 of the 2 traits, $\mathrm{g}$ is a vector of the genetic markers effects attributed to chromosome $i$, and $\mathbf{e}$ is the vector of residuals. Normality of $\mathbf{g}_{i}$ is assumed where $\mathbf{g}_{i} \approx N\left(0, \mathbf{G}_{i} \sigma_{g_{i}}^{2}\right)$ and $\mathbf{G}_{i}$ is the GRM built for chromosome $i$. The proportion of genetic variance attributed to each chromosome was computed following the method proposed by Yang et al. (2011b).

\section{RESULTS}

\section{Phenotypic Elements}

Only minor changes were observed in the score prevalence once phenotypic data were filtered (Table 1).
Groups of affected/nonaffected animals were less balanced for PMG. Only $3.1 \%$ of the animals were affected by PMG, although the affected animals represented $17.6 \%$ of the data by UCT. Overall prevalence of nonclear udders (codes 1 to 8 ) decreased over the years as the prevalence of highly aggravating abnormalities such as ramal teats was reduced (Figure 2). The prevalence of SNT, with or without supernumerary mammary gland tissue (codes 3 to 7 ), stayed stable over time (Figure 2). The SNT prevalence was $6 \%$ lower for cows whose dam was a heifer during their embryological development. Heritability estimates were 0.28 and 0.15 for UCT and PMG, respectively. Heritability estimates of both traits had standard errors below 0.01 for each run. The EBV and deregressed EBV of the bulls selected for the GWAS analysis reached reliabilities higher than 0.5. Reliabilities for UCT were consistently higher than for PMG (Table 2). When observed by year of birth of the bulls, the EBV, as expected, did not change over time (Figure 3).

\section{Association Studies}

Genome-wide association studies using the imputed genotypes revealed a significantly associated region on BTA 5 for UCT and PMG (Figure 4). A total of 468 and 108 SNP on BTA 5 were significantly associated with UCT and PMG, respectively. The SNP significantly associated with UCT were within 1.1 megabases

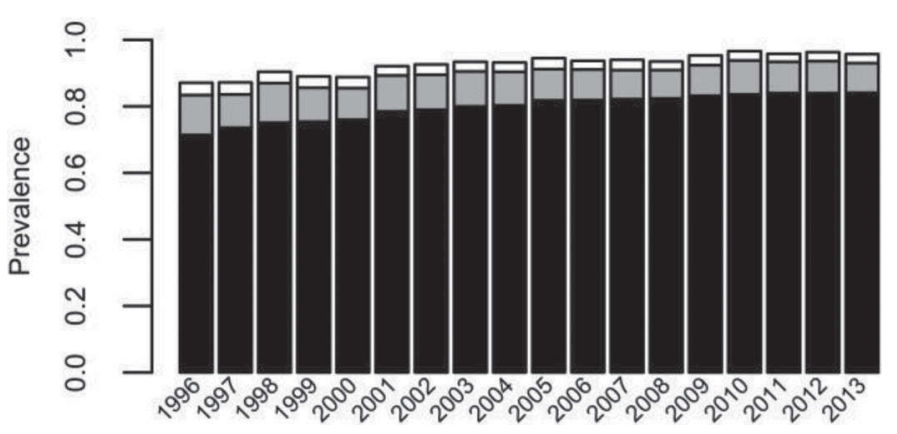

Figure 2. Change of the codes for clear udder (code 9, black) and supernumerary teats (SNT) with mammary gland tissue (codes 3 and 5 , white) or without (codes 4, 6, and 7, gray) relative to all records over the years 1996 to 2013 . 


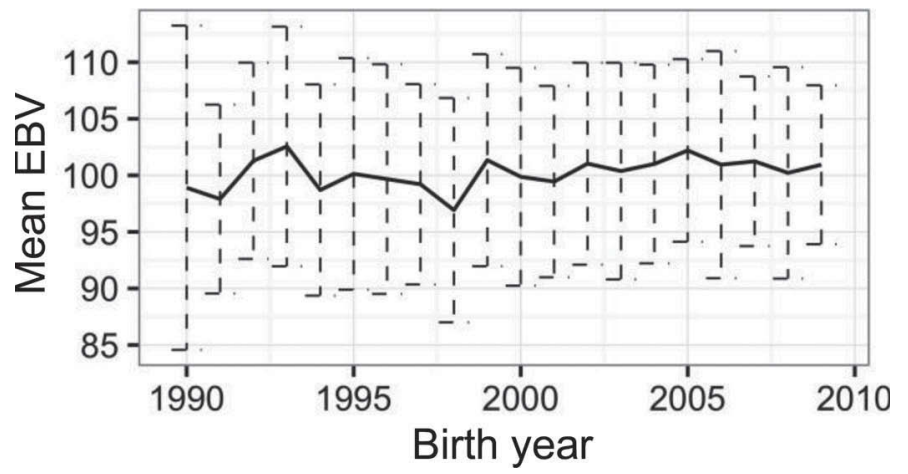

Figure 3. Mean EBV for udder clearance of the sires born in a same year. Dotted lines represent the standard deviations. Values were set on a basis at 100 with a genetic standard deviation of 12 .

(Mb; Figure 5). Reducing the SNP panel from WGS to medium density, the same region still appeared significantly associated with SNT (Supplemental Figure S1; https://doi.org/10.3168/jds.2016-11420). No significant SNP were found in any other genomic region after Bonferroni correction for multiple testing. Genomic inflation was low applying the mixed-model approach (0.97 and 0.99 for UCT and PMG, respectively). The Q-Q plots of both GWAS also showed the soundness of the analysis (Figure 6). Comparing PMG to UCT revealed 2 regions, one on BTA 17 and one on BTA 20, that reached markedly lower $P$-values for PMG than for UCT $\left(P<10^{-7}\right.$ vs. $\left.P<10^{-4}\right)$. The regions showing stronger associations on BTA 17 and BTA 20 are clearly seen in Figure 4b. The 11 SNP on BTA 5 with the lowest $P$-values for both trait definitions were the same and present in the SNP list of Run5 of the 1000 Bulls Genome Project (Daetwyler et al., 2014) but not on any chip of lower density. Table 3 lists the 20 SNP most highly associated with SNT, their positions on BTA 5, their effects, and their $P$-values.

\section{Genetic Variance Distribution Over the Genome}

Distribution of the explained genetic variance was computed for both traits, plotted by chromosome (Figure 7) and compared with the results of the GWAS. All WGS variants explained 74.9 and $53.8 \%$ of the genetic variance for UCT and PMG, respectively. BTA 5 explained a high proportion of variance for PMG and UCT (5.3 and 9.7\%, respectively). Proportions of the genetic variance explained on BTA 9, BTA 11, and BTA 14 were markedly higher for UCT than for PMG.

\section{Gene Content in the Associated Regions}

Analysis identified a region of $1.1 \mathrm{Mb}$ on BTA 5 associated with both traits. The $P$-values were markedly
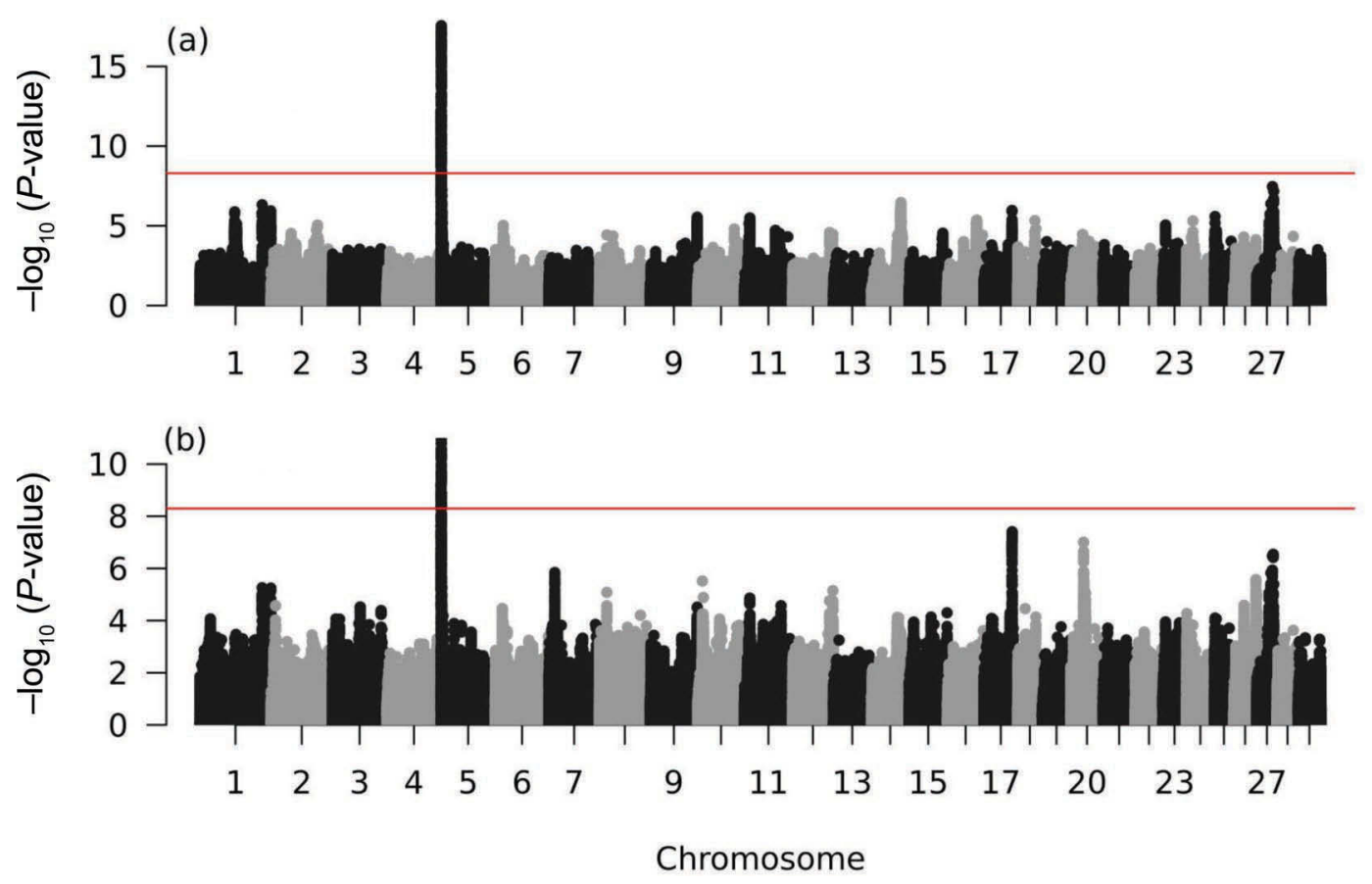

Figure 4. Manhattan plots presenting the association between the imputed bulls whole sequence variants and their deregressed proofs for udder clearance (a) and supernumerary mammary gland tissue (b). Horizontal line represents the Bonferroni corrected significance level $(P<$ $\left.5.0811 \times 10^{-9}\right)$. Color version available online. 


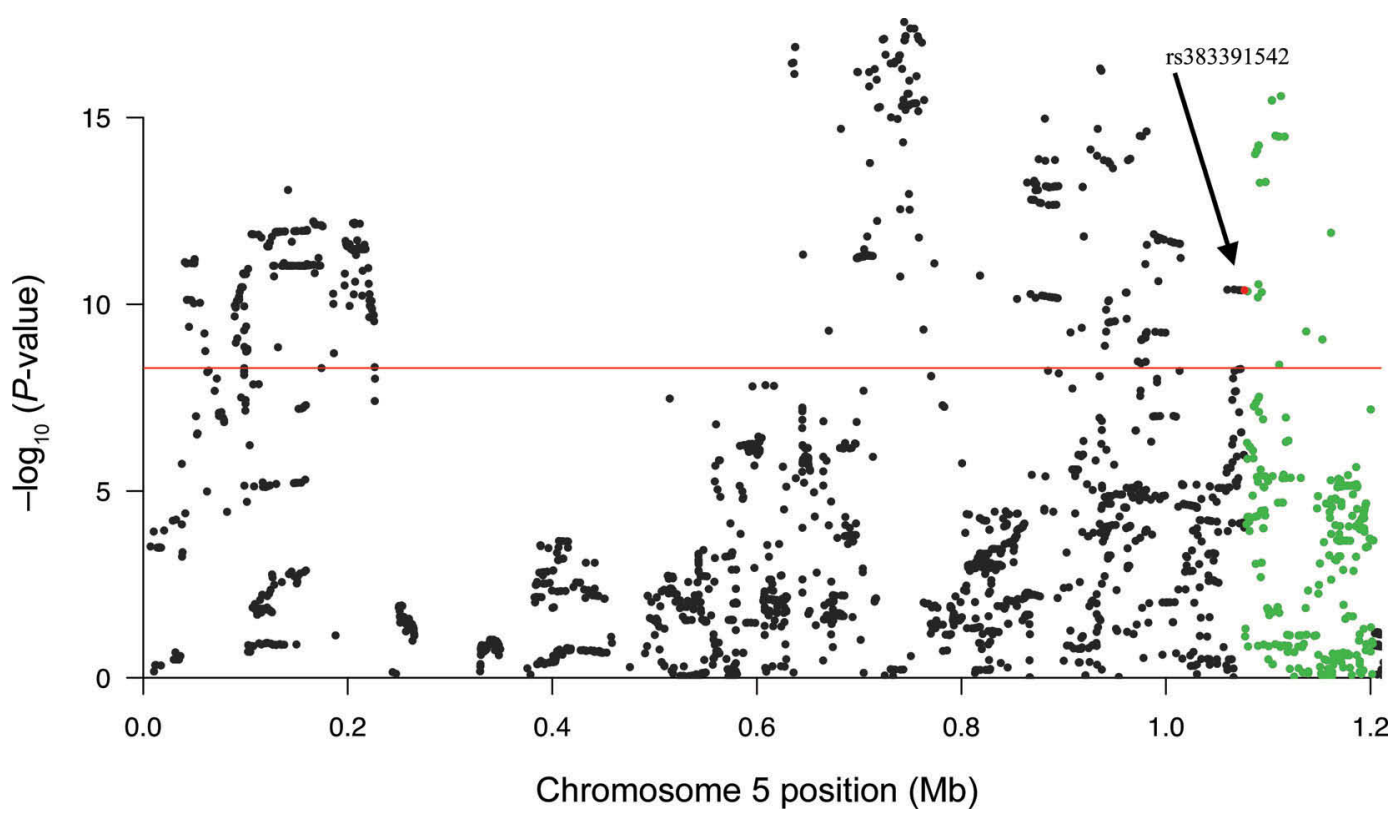

Figure 5. Manhattan plot presenting the region of BTA 5 where all associated SNP are found. The gray (green) dots represent the variants within the LGR 5 gene and the arrowed (red) dot is rs383391542, a synonymous mutation of the same gene. Color version available online.

lower for PMG than for UCT on part of BTA 17 and BTA 20, suggesting specific associations for live SNT. Two regions of approximately $1 \mathrm{Mb}$ on these chromosomes were considered for gene content analysis (Table $4)$.

Of the significantly associated SNP on BTA 5, only one was within a coding region. The rs383391542 is a synonymous variant of the first exon at the $5^{\prime}$ end of the leucine-rich repeat-containing G-protein coupled receptor 5 (Figure 5). This receptor acts as an upregulator of the Wnt signaling pathway (Plaks et al., 2013).
The ankyrin repeat domain containing the protein-like coding sequence of $\mathrm{LOC78893}$ in the vicinity is also involved in the regulation of the Wnt signaling pathway (Schwarz-Romond et al., 2002). On BTA 17, TBX5 is located next to TBX3 and these genes lay within 100 kilobases of the SNP with the lowest $P$-values on this chromosome for PMG. Deletion of both genes induces ulnar-mammary syndrome, a disorder characterized by missing mammary glands in humans (Bamshad et al., 1997; Borozdin et al., 2006). A mutation in TBX5 is responsible for the Holt-Oram syndrome in humans, a
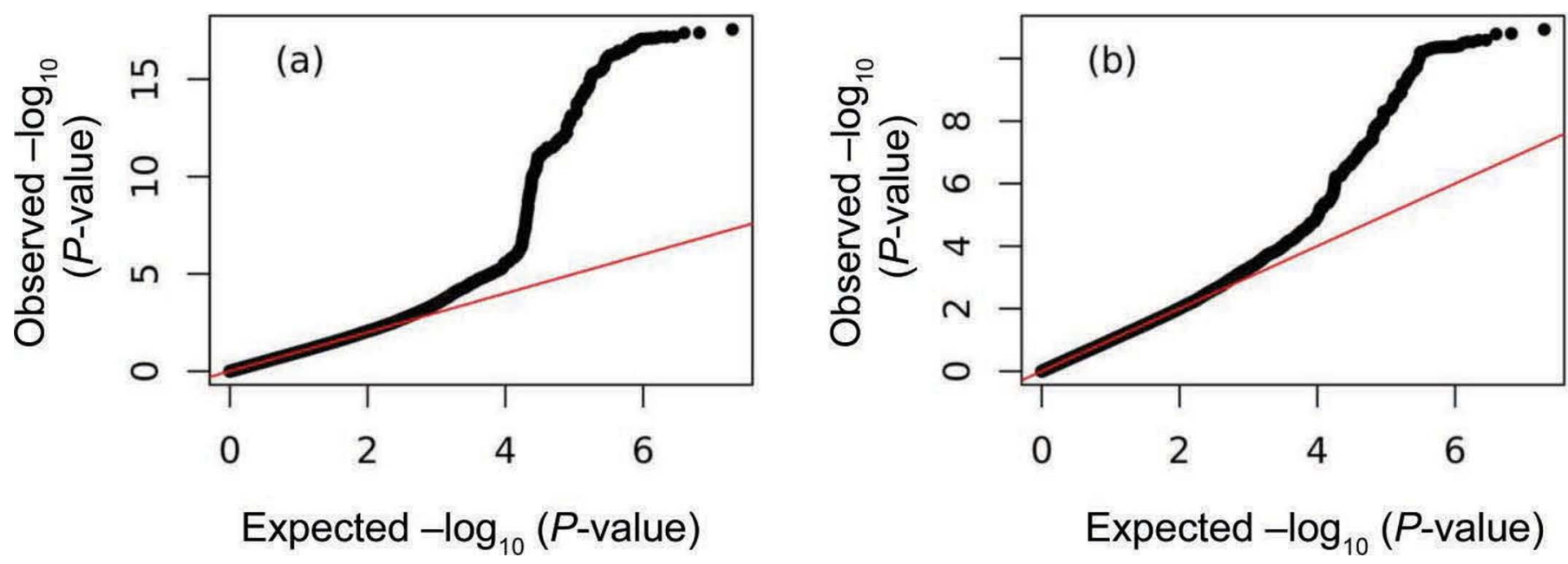

Figure 6. Q-Q plots of the genome-wide association study for udder clearance (a) and supernumerary mammary gland tissue (b). Color version available online. 
Table 3. The 20 SNP most highly associated with supernumerary teats (SNT), their position on BTA 5, their alternate alleles, and their effects and $P$-values for both traits ${ }^{1}$

\begin{tabular}{|c|c|c|c|c|c|c|}
\hline \multirow[b]{2}{*}{ SNP } & \multirow[b]{2}{*}{ Position } & \multirow[b]{2}{*}{$\begin{array}{l}\text { Effect } \\
\text { allele }\end{array}$} & \multicolumn{2}{|c|}{ UCT } & \multicolumn{2}{|c|}{ PMG } \\
\hline & & & $\begin{array}{c}\text { Absolute } \\
\text { effect }\end{array}$ & $P$-value & $\begin{array}{c}\text { Absolute } \\
\text { effect }\end{array}$ & $P$-value \\
\hline rs137045763 & 635822 & $\mathrm{~A}$ & 3.58 & $3.39 \mathrm{E}-17$ & & \\
\hline rs109066101 & 637373 & A & 3.58 & $1.30 \mathrm{E}-17$ & 3.14 & $4.38 \mathrm{E}-11$ \\
\hline rs110009085 & 637620 & $\mathrm{G}$ & 3.58 & $1.29 \mathrm{E}-17$ & 3.15 & $4.07 \mathrm{E}-11$ \\
\hline rs110996035 & 723104 & G & 3.62 & $8.13 \mathrm{E}-18$ & 3.16 & $3.88 \mathrm{E}-11$ \\
\hline rs208934657 & 724473 & $\mathrm{~T}$ & 3.61 & $7.76 \mathrm{E}-18$ & 3.16 & $4.31 \mathrm{E}-11$ \\
\hline rs109241627 & 725840 & G & 3.55 & $2.08 \mathrm{E}-17$ & & \\
\hline rs109839954 & 735235 & A & 3.54 & $3.16 \mathrm{E}-17$ & & \\
\hline rs41621172 & 738426 & G & 3.60 & $2.84 \mathrm{E}-17$ & & \\
\hline rs110485301 & 739135 & $\mathrm{C}$ & 3.68 & $2.20 \mathrm{E}-17$ & & \\
\hline rs109934239 & 739858 & $\mathrm{C}$ & 3.69 & $2.15 \mathrm{E}-17$ & 3.27 & $4.25 \mathrm{E}-11$ \\
\hline rs209692771 & 744101 & $\mathrm{~A}$ & 3.96 & $2.76 \mathrm{E}-18$ & 3.52 & $1.17 \mathrm{E}-11$ \\
\hline rs136739500 & 744288 & $\mathrm{G}$ & 3.86 & $8.56 \mathrm{E}-18$ & 3.41 & $2.96 \mathrm{E}-11$ \\
\hline rs109324630 & 744787 & $\mathrm{~A}$ & 3.86 & $8.49 \mathrm{E}-18$ & 3.41 & $2.95 \mathrm{E}-11$ \\
\hline rs211170870 & 745323 & G & 3.87 & $6.65 \mathrm{E}-18$ & 3.41 & $2.59 \mathrm{E}-11$ \\
\hline rs133518423 & 745597 & $\mathrm{C}$ & 3.87 & $6.53 \mathrm{E}-18$ & 3.41 & $2.57 \mathrm{E}-11$ \\
\hline rs137039258 & 749527 & A & & & 3.18 & $4.53 \mathrm{E}-11$ \\
\hline rs135616391 & 749965 & $\mathrm{C}$ & 3.78 & $4.10 \mathrm{E}-18$ & 3.35 & $1.65 \mathrm{E}-11$ \\
\hline rs385390886 & 752457 & $\mathrm{~A}$ & & & 3.11 & $4.29 \mathrm{E}-11$ \\
\hline rs207846575 & 754008 & $\mathrm{~T}$ & 3.69 & $4.16 \mathrm{E}-18$ & 3.27 & $1.58 \mathrm{E}-11$ \\
\hline rs133466637 & 754366 & $\mathrm{~T}$ & & & 3.11 & $4.24 \mathrm{E}-11$ \\
\hline rs109756155 & 754515 & $\mathrm{~T}$ & & & 3.11 & $4.27 \mathrm{E}-11$ \\
\hline rs109992424 & 755969 & $\mathrm{C}$ & & & 3.10 & $4.22 \mathrm{E}-11$ \\
\hline rs109247756 & 757338 & $\mathrm{~T}$ & 3.66 & $6.63 \mathrm{E}-18$ & 3.21 & $3.20 \mathrm{E}-11$ \\
\hline rs110753335 & 758256 & $\mathrm{~A}$ & 3.65 & $8.00 \mathrm{E}-18$ & 3.19 & $4.16 \mathrm{E}-11$ \\
\hline rs110493118 & 761395 & G & 3.64 & $9.82 \mathrm{E}-18$ & & \\
\hline
\end{tabular}

${ }^{1} \mathrm{UCT}=$ udder clearance; PMG $=$ supernumerary mammary gland tissue.

malformation of the extremities and the heart (Holt and Oram, 1960; Li et al., 1997; Basson et al., 1997). The protein encoded by $T B X 3$ is also a downstream target of the canonical Wnt pathway (Renard et al., 2007). Only embigin and the poly (ADP-ribose) polymerase

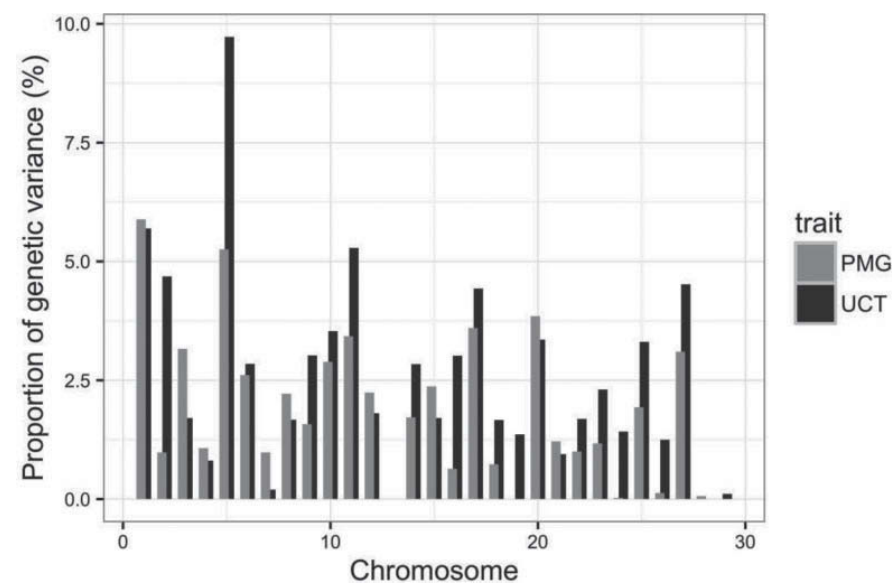

Figure 7. Genetic variance explained by the SNP of each autosomal chromosome. Black bars represent the results for udder clearance (UCT), and gray bars represent the values for supernumerary mammary gland tissue (PMG). The percentage of genetic variance explained by BTA 13 is not zero but is not included because it is on the order of $10^{-4}$. family, member 8 found near the identified region on BTA 20 can be somehow functionally related to SNT. They encode proteins involved in cell development and tissue growth (Guenette et al., 1997; Amé et al., 2004).

\section{DISCUSSION}

This was the first study analyzing the phenotypic trend for SNT over almost 20 yr. Variance component estimation was carried out for 2 trait definitions of SNT in the Swiss Brown Swiss cattle population. The BLUP algorithm was applied for the estimation of breeding values. This is the first genetic evaluation of SNT in this population. Although phenotypically oriented selection against ramal SNT has been performed before data recording, no effective breeding strategy against these malformations has been applied to date. As a consequence, only minor changes have been observed in the prevalence of SNT phenotypes over the last $20 \mathrm{yr}$. Although a minor change in the phenotype prevalence was observed, nothing happened at the genetic level. This stable situation denotes that SNT were not selected for indirectly with any other trait as Wiener (1962) already claimed based upon milk yield. Slow reduction of the prevalence of ramal SNT and of second orifices on main teat can be explained by the detrimental effects of 
these phenotypes on milk production. Cows with these malformations were culled early in life and thus did not pass their genes on to offspring. Heritability estimates achieved are concordant with previous studies (Brka et al., 2002; Pausch et al., 2012). Joerg et al. (2014) looked only at blind SNT placed at the rear of the udder with an estimated heritability of 0.64 . Such a high estimate may be explained by a more specific trait definition. Similarly, lower heritability was expected and obtained for PMG than UCT, as clear animals and carriers of blind SNT were mixed in the same group. Furthermore, reliabilities of EBV and deregressed EBV were lower for PMG than for UCT. With respect to including SNT in a breeding program, we suggest using UCT as a phenotype for this trait. A more comprehensive definition of SNT could include the codes 1, 2, and 8; however, these were removed from the present study to achieve an unambiguous trait definition for gene discovery.

Genomic inflation factors reached values deviating less than 0.03 points from 1 , and Q-Q plots (Figure 6) prove how well the mixed-model approach coped with the population structure. A main gene effect present in phenotypic data and not taken in account in the mixed-model used for association discovery leads to "inaccurate estimation of variance parameters under the null hypothesis" as presented by Kang et al. (2010). This kind of inaccuracy in the GWAS model can result in genomic deflation, as in the present study.

Denser genotypic data than than used by Pausch et al. (2012) or Joerg et al. (2014) combined with 2 different trait definitions give further insight into the genetic architecture of hyperthelia and its 2-step development. The 2-step development of complete teats was mostly studied in mice and is reviewed by Hens and Wysolmerski (2005). Although indicating a predominant major effect on BTA 5 (Figure 4), analyses carried out here underline a distinct polygenic character of SNT. Supporting this statement, the proportion of genetic variance was unevenly distributed over the whole genome (Figure 7), although a great proportion of the genetic variance was captured by the sequence variants. Pausch et al. (2012) also described an effect on BTA 5 in the German Fleckvieh. Using SNP chip data of medium density (Illumina BovineSNP50), they revealed 4 QTL influencing the presence of SNT but could not define any specific gene as a candidate for the effect on BTA 5. With denser genotypic information, one can consider the leucine-rich repeat containing $\mathrm{G}$ protein-coupled receptor 5 as a candidate gene for SNT for 3 reasons. First, expression level of $L G R 5$ has a direct effect on mammary gland tissue development (Plaks et al., 2013). Second, functional studies in mice attested to its role as an upregulator of the canonical Wnt signaling pathway (Schwarz-Romond et al., 2002). This pathway is involved in many embryonic development processes and Alexander et al. (2012) explained how the Wnt complexes were especially responsible for the appearance of mammary tissues during the embryogenesis. The same author presented specific patterns of Wnt upregulation leading to breast cancer in human. Similarly, higher expression of Wnt elements during embryonic mammogenesis could lead to the formation of supernumerary placodes and thus to SNT. Finally, a synonymous mutation within the sequence of $L G R 5$ is associated with SNT. The SNP rs383391542 could not have been found in former studies, as it is not included in any bovine Illumina chip assay. Synonymous mutations have been shown to influence mRNA folding and stability, thereby having a functional effect on the gene of which they are a part (Buske et al., 2013).

Results of our GWAS for UCT point out the region on BTA 5 only, but emphasizing live SNT as it was done for PMG, 2 additional regions presenting markedly lower $P$-values than the general background on BTA 17 and BTA 20 were identified. These differences between our traits can be explained by a 2 -phase development of the prenatal mammary tissues. TBX5 was contained within the region associated only with PMG on BTA 17. This gene causes Holt-Oram syndrome in human, a malformation without any direct link to mammary development. However, deleted in combination with $T B X 3$, which is approximately $1 \mathrm{Mb}$ apart on the same chromosome, it induces the Ulnar-mammary syndrome for which mammary hypoplasia is a main symptom (Bamshad et al., 1997; Borozdin et al., 2006). TBX3 is induced by Wnt genes, but also induces other Wnt genes (Hens and Wysolmerski, 2005). Joerg et al. (2014) discovered a region on BTA 20 linked with blind

Table 4. Significant SNP associated with udder clearance (UCT) and supernumerary mammary gland tissue (PMG) and genes in the regions of the associated SNP

\begin{tabular}{|c|c|c|c|c|c|}
\hline Chromosome & $\begin{array}{c}\text { Position } \\
\text { (interval in bp) }\end{array}$ & \multicolumn{2}{|c|}{ Significant SNP } & \multicolumn{2}{|c|}{ Genes in regions associated } \\
\hline $\begin{array}{l}\text { BTA } 5 \\
\text { BTA } 17 \\
\text { BTA } 20\end{array}$ & $\begin{array}{c}40,800-1,160,000 \\
62,180,000-63,180,000 \\
28,130,000-29,350,000\end{array}$ & 468 & 108 & $\begin{array}{l}\text { TBX3, TBX5 } \\
\text { EMB, PARP } 8\end{array}$ & LOC783893, LGR5 \\
\hline
\end{tabular}


caudal SNT. However, they could not identify any gene functionally linked with this trait in the region. Similarly the region on BTA 20 affecting PMG in our study does not indicate any specific relation to SNT. Two neighboring genes, $E M B$ and $P A R P 8$, are involved in cell growth and development (Guenette et al., 1997; Amé et al., 2004). These genes do not have any known specific function related to mammary gland tissue development so far, but may be active during teat formation, independent of whether these are supernumerary or not.

Through the differential trait definition for the same SNT data, the 2-step development of SNT (teat formation vs. mammary gland tissue development) may have been captured, at least in part, in the present study. However, regions on BTA 17 and BTA 20 should be further investigated to find coding or noncoding sequences that have a function linked to SNT.

\section{CONCLUSIONS}

Use of imputed whole-genome sequence variants identified a significantly associated region with UCT and PMG on BTA 5. LGR5 has been pointed out as candidate gene due to its location and strong association with SNT. Differences in association could be detected with 2 trait definitions relying on the same records. Emphasis on live SNT suggested 2 supplemental QTL on BTA 17 and BTA 20. Implementation of the outcome from this study, even using genotypic data of lower density than the whole-genome sequence, as a routine application will enable the reduction of SNT in the Swiss BS cattle population. Because the surgical removal of SNT may become controversial, breeders may need to reduce the prevalence of SNT by breeding. Based on our results, genomic selection could enable a rapid reduction of the phenotype discussed here.

\section{ACKNOWLEDGMENTS}

Braunvieh Schweiz provided the phenotypic data. We acknowledge the InterGenomics partners (Braunvieh Schweiz, Switzerland; Arbeitsgemeinschaft der Österreichischen Braunviehzüchter, Austria; Arbeitsgemeinschaft Deutsches Braunvieh, Germany; Associazione nazionale allevatori bovini della razza Bruna, Italy; Brown Swiss Association of the US; Brune Genetique Services, France; and Zveza rejcev govedi rjave pasme Slovenije, Slovenia), and also the partners of the LowInputBreed project (EU Grant agreement No 222 623: Swissgenetics, Switzerland; agn Genetics GmBH, Switzerland; Braunvieh Schweiz, Switzerland; Research Institute of Organic Agriculture (FiBL), Switzerland; and the University of Göttingen, Germany) for giving us the permission to use their genotypic data for imputation. The 1000 Bulls Genome Project is acknowledged for providing the genotypes of the reference panel for imputation. Computations were done at the server facilities of Qualitas AG, Zug, Switzerland.

\section{REFERENCES}

Alexander, C. M., S. Goel, S. A. Fakhraldeen, and S. Kim. 2012. Wnt signaling in mammary glands: Plastic cell fates and combinatorial signaling. Cold Spring Harb. Perspect. Biol. 4: https://doi. org $/ 10.1101 /$ cshperspect.a008037.

Amé, J.-C., C. Spenlehauer, and G. de Murcia. 2004. The PARP superfamily. BioEssays 26:882-893. https://doi.org/10.1002/bies.20085.

Bamshad, M., R. C. Lin, D. J. Law, W. C. Watkins, P. A. Krakowiak, M. E. Moore, P. Franceschini, R. Lala, L. B. Holmes, T. C. Gebuhr, B. G. Bruneau, A. Schinzel, J. G. Seidman, C. E. Seidman, and L. B. Jorde. 1997. Mutations in human TBX3 alter limb, apocrine and genital development in ulnar-mammary syndrome. Nat. Genet. 16:311-315. https://doi.org/10.1038/ng0797-311.

Basson, C. T., D. R. Bachinsky, R. C. Lin, T. Levi, J. A. Elkins, J. Soults, D. Grayzel, E. Kroumpouzou, T. A. Traill, J. LeblancStraceski, B. Renault, R. Kucherlapati, J. G. Seidman, and C. E. Seidman. 1997. Mutations in human TBX5 [corrected] cause limb and cardiac malformation in Holt-Oram syndrome. Nat. Genet. 15:30-35. https://doi.org/10.1038/ng0197-30.

Bigler, A. 2015. Neue Logos im Toro Spezial. Toro 8:7.

Borozdin, W., A. M. Bravo-Ferrer Acosta, E. Seemanova, M. Leipoldt, M. J. Bamshad, S. Unger, and J. Kohlhase. 2006. Contiguous hemizygous deletion ofTBX5,TBX3, andRBM19 resulting in a combined phenotype of Holt-Oram and ulnar-mammary syndromes. Am. J. Med. Genet. A. 140A:1880-1886. https://doi. org/10.1002/ajmg.a.31340.

Brka, M., N. Reinsch, and E. Kalm. 2002. Frequency and heritability of supernumerary teats in German Simmental and German Brown Swiss cows. J. Dairy Sci. 85:1881-1886. https://doi.org/10.3168/ jds.S0022-0302(02)74262-8.

Browning, B. L., and S. R. Browning. 2009. A unified approach to genotype imputation and haplotype-phase inference for large data sets of trios and unrelated individuals. Am. J. Hum. Genet. 84:210-223. https://doi.org/10.1016/j.ajhg.2009.01.005.

Buske, O. J., A. Manickaraj, S. Mital, P. N. Ray, and M. Brudno. 2013. Identification of deleterious synonymous variants in human genomes. Bioinformatics 29:1843-1850. https://doi.org/10.1093/ bioinformatics/btt308.

Cunningham, F., M. R. Amode, D. Barrell, K. Beal, K. Billis, S. Brent, D. Carvalho-Silva, P. Clapham, G. Coates, S. Fitzgerald, L. Gil, C. G. Girón, L. Gordon, T. Hourlier, S. E. Hunt, S. H. Janacek, N. Johnson, T. Juettemann, A. K. Kähäri, S. Keenan, F. J. Martin, T. Maurel, W. McLaren, D. N. Murphy, R. Nag, B. Overduin, A. Parker, M. Patricio, E. Perry, M. Pignatelli, H. S. Riat, D. Sheppard, K. Taylor, A. Thormann, A. Vullo, S. P. Wilder, A. Zadissa, B. L. Aken, E. Birney, J. Harrow, R. Kinsella, M. Muffato, M. Ruffier, S. M. J. Searle, G. Spudich, S. J. Trevanion, A. Yates, D. R. Zerbino, and P. Flicek. 2015. Ensembl 2015. Nucleic Acids Res. 43:D662-D669. https://doi.org/10.1093/nar/gku1010.

Daetwyler, H. D., A. Capitan, H. Pausch, P. Stothard, R. van Binsbergen, R. F. Brøndum, X. Liao, A. Djari, S. C. Rodriguez, C. Grohs, D. Esquerré, O. Bouchez, M.-N. Rossignol, C. Klopp, D. Rocha, S. Fritz, A. Eggen, P. J. Bowman, D. Coote, A. J. Chamberlain, C. Anderson, C. P. VanTassell, I. Hulsegge, M. E. Goddard, B. Guldbrandtsen, M. S. Lund, R. F. Veerkamp, D. A. Boichard, R. Fries, and B. J. Hayes. 2014. Whole-genome sequencing of 234 bulls facilitates mapping of monogenic and complex traits in cattle. Nat. Genet. 46:858-865. https://doi.org/10.1038/ng.3034.

Devlin, B., and K. Roeder. 1999. Genomic control for association studies. Biometrics 55:997-1004. https://doi.org/10.1111/j.0006341X.1999.00997.x. 
Garrick, D. J., J. F. Taylor, and R. L. Fernando. 2009. Deregressing estimated breeding values and weighting information for genomic regression analyses. Genet. Sel. Evol. 41:55 https://doi. org/10.1186/1297-9686-41-55.

Groeneveld, E., M. Kovac, and N. Mielenz. 2010. VCE User's Guide and Reference Manual Version 6.0.

Guenette, R. S., S. Sridhar, M. Herley, M. Mooibroek, P. Wong, and M. Tenniswood. 1997. Embigin, a developmentally expressed member of the immunoglobulin super family, is also expressed during regression of prostate and mammary gland. Dev. Genet. 21:268-278.

Hens, J. R., and J. J. Wysolmerski. 2005. Key stages of mammary gland development: molecular mechanisms involved in the formation of the embryonic mammary gland. Breast Cancer Res. 7:220224. https://doi.org/10.1186/bcr1306.

Holt, M., and S. Oram. 1960. Familial heart disease with skeletal malformations. Br. Heart J. 22:236-242.

Howie, B., C. Fuchsberger, M. Stephens, J. Marchini, and G. R. Abecasis. 2012. Fast and accurate genotype imputation in genomewide association studies through pre-phasing. Nat. Genet. 44:955959. https://doi.org/10.1038/ng.2354.

Joerg, H., C. Meili, O. Ruprecht, E. Bangerter, A. Burren, and A. Bigler. 2014. A genome-wide association study reveals a QTL influencing caudal supernumerary teats in Holstein cattle. Anim. Genet. 45:871-873. https://doi.org/10.1111/age.12215.

Kang, H. M., J. H. Sul, S. K. Service, N. A. Zaitlen, S.-Y. Kong, N. B. Freimer, C. Sabatti, and E. Eskin. 2010. Variance component model to account for sample structure in genome-wide association studies. Nat. Genet. 42:348-354. https://doi.org/10.1038/ng.548.

Li, Q. Y., R. A. Newbury-Ecob, J. A. Terrett, D. I. Wilson, A. R. Curtis, C. H. Yi, T. Gebuhr, P. J. Bullen, S. C. Robson, T. Strachan, D. Bonnet, S. Lyonnet, I. D. Young, J. A. Raeburn, A. J. Buckler, D. J. Law, and J. D. Brook. 1997. Holt-Oram syndrome is caused by mutations in TBX5, a member of the Brachyury (T) gene family. Nat. Genet. 15:21-29. https://doi.org/10.1038/ng0197-21.

McLaren, W., B. Pritchard, D. Rios, Y. Chen, P. Flicek, and F. Cunningham. 2010. Deriving the consequences of genomic variants with the Ensembl API and SNP effect predictor. Bioinformatics 26:2069-2070. https://doi.org/10.1093/bioinformatics/btq330.

Misztal, I., S. Tsuruta, T. Strabel, B. Auvray, T. Druet, and D. H. Lee. 2002. BLUPF90 and related programs (BGF90). Commun. No. 28-07 in 7th World Congress on Genetics Applied to Livestick Production, Montpellier, France.

Neumaier, A., and E. Groeneveld. 1998. Restricted maximum likelihood estimation of covariances in sparse linear models. Genet. Sel. Evol. 30:3-26.

Pausch, H., B. Aigner, R. Emmerling, C. Edel, K.-U. Götz, and R. Fries. 2013. Imputation of high-density genotypes in the Fleckvieh cattle population. Genet. Sel. Evol. 45:3 https://doi. org/10.1186/1297-9686-45-3.

Pausch, H., S. Jung, C. Edel, R. Emmerling, D. Krogmeier, K.-U. Götz, and R. Fries. 2012. Genome-wide association study uncovers four QTL predisposing to supernumerary teats in cattle. Anim. Genet. 43:689-695. https://doi.org/10.1111/j.1365-2052.2012.02340.x.

Plaks, V., A. Brenot, D. A. Lawson, J. R. Linnemann, E. C. Van Kappel, K. C. Wong, F. de Sauvage, O. D. Klein, and Z. Werb. 2013. Lgr5-expressing cells are sufficient and necessary for postnatal mammary gland organogenesis. Cell Reports 3:70-78. https:// doi.org/10.1016/j.celrep.2012.12.017.

Renard, C.-A., C. Labalette, C. Armengol, D. Cougot, Y. Wei, S. Cairo, P. Pineau, C. Neuveut, A. de Reyniès, A. Dejean, C. Per- ret, and M.-A. Buendia. 2007. Tbx3 is a downstream target of the Wnt/beta-catenin pathway and a critical mediator of beta-catenin survival functions in liver cancer. Cancer Res. 67:901-910. https:// doi.org/10.1158/0008-5472.CAN-06-2344.

Sargolzaei, M., J. P. Chesnais, and F. S. Schenkel. 2014. A new approach for efficient genotype imputation using information from relatives. BMC Genomics 15:478 https://doi.org/10.1186/14712164-15-478.

Schmidt, H. 1896. Über normale Hyperthelie menschlischer Embryonen. Anat. Anz. 11:702-711.

Schwarz-Romond, T., C. Asbrand, J. Bakkers, M. Kühl, H.-J. Schaeffer, J. Huelsken, J. Behrens, M. Hammerschmidt, and W. Birchmeier. 2002. The ankyrin repeat protein Diversin recruits Casein kinase Iepsilon to the beta-catenin degradation complex and acts in both canonical Wnt and Wnt/JNK signaling. Genes Dev. 16:2073-2084. https://doi.org/10.1101/gad.230402.

Skjervold, H. 2010. Supernumerary Teats in Cattle. Hereditas 46:7174. https://doi.org/10.1111/j.1601-5223.1960.tb03079.x.

Steiger, H. U., and R. Grünenfelder. 1988. Zusatzzitzen. SimmentalerFleckvieh. 86-95.

Tsuruta, S., I. Misztal, and I. Strandén. 2001. Use of the preconditioned conjugate gradient algorithm as a generic solver for mixedmodel equations in animal breeding applications. J. Anim. Sci. 79:1166-1172.

Vasseur, E., F. Borderas, R. I. Cue, D. Lefebvre, D. Pellerin, J. Rushen, K. M. Wade, and A. M. de Passillé. 2010. A survey of dairy calf management practices in Canada that affect animal welfare. J. Dairy Sci. 93:1307-1315. https://doi.org/10.3168/jds.2009-2429.

Weigel, K. A., G. de Los Campos, A. I. Vazquez, G. J. M. Rosa, D. Gianola, and C. P. Van Tassell. 2010. Accuracy of direct genomic values derived from imputed single nucleotide polymorphism genotypes in Jersey cattle. J. Dairy Sci. 93:5423-5435. https://doi. org/10.3168/jds.2010-3149.

Wiener, G. 1962. Supernumerary teats in cattle. Z. Tierzuecht. Zuechtungsbiol. 77:382-392. https://doi.org/10.1111/j.1439-0388.1962. tb01265.x.

Yang, J., B. Benyamin, B. P. McEvoy, S. Gordon, A. K. Henders, D. R. Nyholt, P. A. Madden, A. C. Heath, N. G. Martin, G. W. Montgomery, M. E. Goddard, and P. M. Visscher. 2010. Common SNPs explain a large proportion of the heritability for human height. Nat. Genet. 42:565-569. https://doi.org/10.1038/ng.608.

Yang, J., S. H. Lee, M. E. Goddard, and P. M. Visscher. 2011a. GCTA: A tool for genome-wide complex trait analysis. Am. J. Hum. Genet. 88:76-82. https://doi.org/10.1016/j.ajhg.2010.11.011.

Yang, J., T. A. Manolio, L. R. Pasquale, E. Boerwinkle, N. Caporaso, J. M. Cunningham, M. de Andrade, B. Feenstra, E. Feingold, M. G. Hayes, W. G. Hill, M. T. Landi, A. Alonso, G. Lettre, P. Lin, H. Ling, W. Lowe, R. A. Mathias, M. Melbye, E. Pugh, M. C. Cornelis, B. S. Weir, M. E. Goddard, and P. M. Visscher. 2011b. Genome partitioning of genetic variation for complex traits using common SNPs. Nat. Genet. 43:519-525. https://doi.org/10.1038/ng.823.

Zimin, A. V., A. L. Delcher, L. Florea, D. R. Kelley, M. C. Schatz, D. Puiu, F. Hanrahan, G. Pertea, C. P. Van Tassell, T. S. Sonstegard, G. Marçais, M. Roberts, P. Subramanian, J. A. Yorke, and S. L. Salzberg. 2009. A whole-genome assembly of the domestic cow, Bos taurus. Genome Biol. 10:R42 https://doi.org/10.1186/ gb-2009-10-4-r42. 